\title{
EDUCAÇÃO REMOTA E PANDEMIA EM CLOSE-UP
}

\author{
REMOTE LEARNING AND THE PANDEMIC: A CLOSE-UP
}

EDUCACIÓN A DISTANCIA Y PANDEMIAS DE PRIMER PLANO

\author{
Rosimeri de Oliveira Dias ${ }^{1}$ 0000-0001-9250-1010 \\ Liliana Secron ${ }^{2}$ 0000-0002-9109-7498 \\ Líbia Busquet ${ }^{3}$ 0000-0002-5544-0842
}

\begin{abstract}
${ }^{1}$ Universidade do Estado do Rio de Janeiro - Rio de Janeiro, Rio de Janeiro, Brasil; rosimeri.dias@uol.com.br

${ }^{2}$ Secretaria Municipal de Educação do Município do Rio de Janeiro - Rio de Janeiro, Rio de Janeiro, Brasil; 1secron@gmail.com

${ }^{3}$ Fundação Municipal de Educação de Niterói - Niterói, Rio de Janeiro, Brasil; mcpessin@gmail.com
\end{abstract}

\section{RESUMO:}

Este é um artigo tecido à seis mãos, por meio do encontro e conversas entre três professoras da rede pública de ensino, duas da escola básica e uma da universidade. Esta tessitura conceitua um encontro como aquilo que ativa um campo problemático, princípio de uma formação inventiva de professores. Colocamos em análise e em intervenção uma educação remota, convocada pelos cenários pandêmicos do presente, e o seu plano close-up, que elimina o corpo em sua totalidade como enunciador. No enquadre de uma tela - de computador e/ou celular - a educação vira foco evidenciando um processo de exclusão em massa, tanto do corpo, como de um quantitativo de estudantes e de professores que não possuem acesso ao mundo remoto. Para tanto, o trabalho se divide em três cenas em close-up, a saber: Cena 1: Pandemia e pandemônio: vai passar!(?); Cena 2: espaços outros e as heterotopias: em uma ofegante epidemia, um pouco de ar para não sufocar; Cena 3/Epílogo: brechas de uma formação inventiva de professores: a evolução da liberdade. A aposta conceitual e metodológica proposta apresenta tomadas que compõem as cenas e funcionam como propagadores da dimensão crítica e de resistência para afirmar modos autogestionários e inventivos de formar que ligam conhecer e viver à um ethos - uma política para a produção de vidas livres, raridades em tempos de educação e controle remotos.

Palavras chave: produção de subjetividade; formação inventiva de professores; heterotopia.

\begin{abstract}
:
This is an article woven by six hands, through meetings and conversations held between three teachers from the public education system, two from middle to high school and one from university. This texture conceptualizes an encounter as what activates a problematic field, the principle of an Teachers inventive formation. We put into analysis and into intervention a remote education, summoned by the pandemic scenarios of the present and its close-up plan, which eliminates the body in its totality as the enunciator. In the frame of a screen - computer and/or cell phone - education becomes the focus, evidencing a process of mass exclusion, both of the body and of a number of students and teachers who do not have access to the remote world. For this purpose, the work is divided into three close-up scenes, namely: Scene 1: Pandemic and pandemonium: will it pass!(?); Scene 2: other spaces and heterotopias: in a panting epidemic, a bit of air so as not to suffocate; Scene 3/Epilogue: gaps of an inventive
\end{abstract}


teacher training: the evolution of freedom. The conceptual and methodological take proposed here presents shots that make up the scenes and that work as propagators of the critical dimension and the resistance to affirm self- managed and inventive ways of forming, that link knowing and living to an ethos - a policy for the making of free lives, rarities in times of remote education and control.

Keywords: production of subjectivity; teachers inventive formation; heterotopia.

\section{RESUMEN:}

Este es un artículo tejido a seis manos, a través de un encuentro y conversaciones entre tres profesores del sistema escolar público, dos de la escuela primaria y uno de la universidad. Esta textura conceptualiza un encuentro como lo que activa un campo problemático, el principio de una formación docente inventiva. Ponemos en análisis e intervención una educación a distancia, convocada por los escenarios pandémicos del presente, y su plano de primer plano, que elimina al cuerpo en su totalidad como enunciador. En el marco de una pantalla -computadora y / o celular- la educación se convierte en un foco, mostrando un proceso de exclusión masiva, tanto del cuerpo como de un número de estudiantes y docentes que no tienen acceso al mundo remoto. Para ello, la obra se divide en tres primeros planos, a saber: Escena 1: Pandemia y pandemónium: ¡pasará! (?); Escena 2: otros espacios y heterotopias: en una epidemia jadeante, un poco de aire para no asfixiarme; Escena 3 / Epílogo: lagunas en una formación docente inventiva: la evolución de la libertad. La apuesta conceptual y metodológica propuesta presenta tomas que componen los escenarios y funcionan como propagadores de la dimensión crítica y la resistencia para afirmar formas autogestionadas e inventivas de formar ese vínculo saber y vivir a un ethos - una política para la producción de vidas libres, rarezas en la educación y tiempos de control remoto.

Palabras clave: producción de subjetividade; formación docente inventiva; heterotopía.

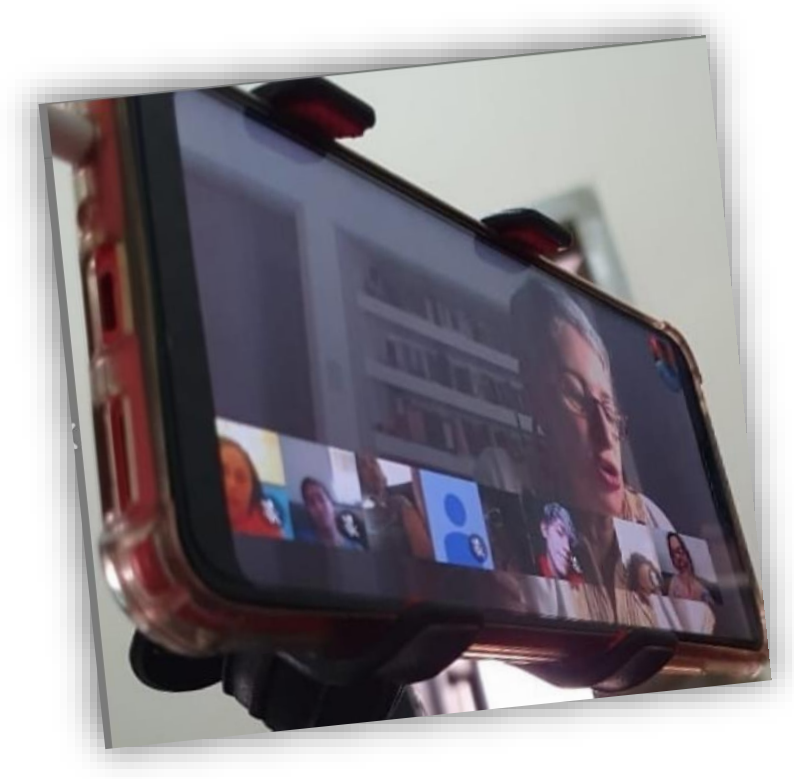

Foto: Sara Busquet

A tomada ou plano é a palavra; a cena ou sequência é a frase, a sentença, a oração; a disposição das tomadas em sua ordem correta - a montagem - é a gramática e a sintaxe. ${ }^{1}$

\footnotetext{
${ }^{1}$ Conversa remota de Ivor Montaguv, no blog "Portal do curta”. Disponível em:

https://portaldocurta.wordpress.com/2012/05/25/tomada-ou-plano-cena-ou-sequenciamontagem/\#: :text=Como\%20a\%20palavra\%20\%C3\%A9\%20a,e\%20depois\%20o\%20E\%20Corta!
} 


\section{Trilha sonora ${ }^{2}$}

Vai passar

Nessa avenida um samba popular Cada paralelepípedo da velha cidade

Essa noite vai se arrepiar

Chico Buarque

Tomada 1: close em seis mãos sobre um teclado de computador que se separam para reaparecer, na tomada 2 , cada par em um computador diferente.

Tomada 2: close na tela de um computador em que as mãos aparecem em pares em três quadradinhos, sobre teclados distintos, em transmissão remota.

As imagens aparecem enquanto os créditos introdutórios passam. A trilha ao fundo, remete ao som de um rádio de pilha. A música: Vai passar (1984), de Chico Buarque e Francis Hime.

Vai passar foi um símbolo da transição para o primeiro governo civil após 21 anos de ditadura militar. Uma crítica dos sombrios tempos e, ao mesmo tempo, uma celebração da resistência e força ativa na produção de realidades outras possíveis e porque não dizer, menos cruéis.

Ela foi escolhida, em primeiro lugar, porque, ao retomar a história de nosso passado recente, nos defronta com a urgência de conversar com o que acontece no presente. Um momento histórico em que se tenta trazer para a "avenida", com novo arranjo, lógicas perigosas de "um passado infeliz de nossa história".

Em segundo lugar, mas não menos importante, por ela, a música, evocar a necessidade de colocar em discussão as ligas entre a crítica do presente e as resistências - que para nós, neste artigo-roteiro, concordando com Deleuze (1997), circula entre a filosofia e a arte - que se configuram como possibilidades outras para o que há entre pandemia e pandemônio ${ }^{3}$.

A pandemia do Covid-194 e a necessidade do distanciamento social, vem, há mais de um ano, mantendo dentro de suas casas, professores e alunos e, ao mesmo tempo, produzindo a urgência de problematizar os efeitos de uma educação forjada remotamente. O pandemônio refere-se ao que estamos vivendo desde, 2016, com o impeachment da presidenta Dilma

\footnotetext{
${ }^{2}$ No decorrer do artigo, você leitor, terá, em close, uma série de aproximações com links que entram como nota para ligar discussões e conceitos com esta escrita coletiva que se pluga em outras territorialidades -

virtuais/remotas - para nos aproximar. Mas esteja livre para seguir com a leitura do artigo, sem linkar, para não dispersar.

${ }^{3}$ Como nos diz Eliane Brun, disponível em: https://www.youtube.com/watch?v=AMr8V6PjGm4\&feature=youtu.be

${ }^{4}$ Temos acompanhado os números de caso e de óbitos, que no término do artigo já estava superior a 627 mil vidas ceifadas, pelo site: https://www.bing.com/covid/local/brazil
} 
Rousseff e a eleição, em 2018, do atual presidente Jair Bolsonaro, provocando uma quebra de direitos no país e, em especial, em 2020, com a pandemia, uma atitude negacionista que contribui para a promoção de milhares de mortes que poderiam ser evitadas.

Na vida em geral e na educação em especial, a emergência passa a ser, dessa forma, de que a vida se mova remotamente. Nesta lógica, buscamos, com este artigo, ampliar a conversa com o que circula nas redes e, com isso, inserir uma série de postagens em sites, blogs, lives e podcasts para ligar crítica e resistência à um modo inventivo de pensar o presente pandêmico e de pandemônio em circulação nos territórios escolares e de formação e poder, talvez, contribuir com a tecitura coletiva de um mundo outro.

Para problematizar este modo remoto de nos mover no presente, de início, buscamos uma definição conceitual da música "Vai passar" que ganha corpo como desejo de expressão daquilo que queremos para o presente: Vai passar a pandemia e o pandemônio! Como? Quando? Com que dispositivos? Vai passar?

\begin{abstract}
A canção começou a ser composta no início de 1984, durante a campanha pelas Diretas, e acabou por se tornar o símbolo musical da chamada Nova República. Em ritmo de samba-enredo, a letra é um saboroso acerto de contas do compositor com o regime que o perseguiu, prendeu, exilou e censurou, mas não conseguiu calar seu talento nem sua identificação com o público e com a luta pela democracia.

Em 1969, no auge da repressão, Chico havia composto "Apesar de Você", samba que se tornou o símbolo da resistência, mesmo proibido de ser tocado em público. No Réveillon de 1984, a ditadura nada podia fazer para impedir a passagem daquele samba popular ${ }^{5}$
\end{abstract}

O "vai passar", do samba popular, vem hoje expressar ao mesmo tempo o desejo de resistir, nosso velho conhecido, e o de nos lançar no desafio de não negar o presente, mas problematizá-lo para forjar saídas, inventar rotas, mesmo enquanto ainda precisamos estar em casa, em distanciamento social, no trabalho remoto, cuidando de si, dos outros e da vida. E, com isso, traz para o centro das discussões da educação, a relação entre discurso, linguagem e produção da existência.

Vivemos, no contexto atual, a urgência cada vez maior de ações de combate a um governo que, mesmo diante do fato do Brasil ter se tornado o epicentro mundial de contaminação, chegando a mais de três mil mortes diárias, ainda assim, se mostra negacionista contestando a letalidade do vírus - "É só uma gripezinha!" ${ }^{-}$, e que vem buscando reprimir com ameaças, processos e prisões, os que a ele criticam.

\footnotetext{
${ }^{5}$ Explicação retirada do site "Memorial da Democracia". Disponível em: http://memorialdademocracia.com.br/card/vai-passar-a-noite-da-ditadura-militar

6 Termo que virou meme no Brasil em função de uma coletiva de imprensa feita no palácio do planalto, em $18 / 03 / 2020$, pelo presidente Jair Bolsonaro, no início do isolamento social provocado pela pandemia do Covid19, em que o mesmo se refere ao vírus como se fosse somente uma gripezinha, como nos mostra o
} 
Nosso país virou uma máquina de geração de incerteza e medo, num mundo que foi cada vez mais nos superficializando, dispersando, imobilizando e controlando nossos corpos. Estamos em meio a uma pandemia. E como se não bastasse, o Brasil escolheu - sim, escolhemos, pelo voto - vivê-la em meio a um pandemônio. A vida, nesse contexto, é dureza e nos afeta... nos toca.... e sua escrita é como nos diz Foucault (2002, p. 143) é tecida pelo próprio corpo, que "transforma a coisa vista ou ouvida em 'forças e sangue' (in vires, in sanguinem)".

E em meio a esse pandemônio, na tela, três histórias se cruzam para pensar o presente em sua dimensão acontecimental ${ }^{7}$, numa experiência única de escrita, movidas pelos atravessamentos no campo da educação. São histórias produzidas por mãos de três professoras de instituições públicas. Uma da universidade, na faculdade de formação de professores, e as outras duas do ensino fundamental, uma em cargo de direção e outra em sala de leitura e docência em língua portuguesa.

São as nossas mãos, em close, colocando em cena um tema que nos mobiliza e afeta, fazendo emergir os sinais que nossos corpos vêm dando de resistência e fragilidade. O motivo? A busca da produção de formas de vida capazes de enfrentar estes duros tempos para ampliar o grau de suportabilidade para experienciar o presente (ROLNIK, 2007).

Ainda não sabemos, ao certo, o que fazer. Nem temos referências em que nos basear. Afinal, não há história de nossa geração que tenha vivido uma pandemia, em tempos de um capitalismo acirrado e vil como o que nos passa. Esse não saber, no entanto, por um lado tornase abertura para a invenção, por outro, quando está aliado a uma estrutura de instabilidade social e política na qual estamos imersos, toma ares de crueldade nos proporcionando a sensação de impotência e medo.

Para afirmar a vida nessa situação, que nos toca, nos afeta e pode nos transformar, trazemos para nossas práticas o exercício proposto na formação inventiva de professores ${ }^{8}$ (DIAS, 2012; 2019): conhecer e viver, mantendo vivo um campo problemático e ampliando o grau de abertura para a experiência presente. Dessa forma, evitamos cair no erro simplista e cômodo de apontar culpados e nos mantemos em movimento, enquanto professoras, pensando e fazendo educação. Para isso, é preciso antes aumentar o grau de suportabilidade ao presente e cuidar de si para nos manter vivas e sãs.

colunista do UOL Leonardo Sakamoto. Disponível em: https://noticias.uol.com.br/colunas/leonardosakamoto/2020/03/20/gripezinha-menosprezo-de-bolsonaro-por-coronavirus-o-tornou-cumplice.htm ${ }^{7}$ Sobre o que estamos chamando aqui de "acontecimento" ver o comentário de Luiz Fuganti disponível em: https://www.youtube.com/watch?v=Sqh29IvjN0w

${ }^{8}$ Como introdução à ideia de formação inventiva de professores, sugerimos a fala da profa. Rosimeri de Oliveira Dias na abertura do I Encontro e conversas sobre formação inventiva de professores, 2010, no canal "siteofip", disponível em: https://www.youtube.com/watch?v=DS-ZvNSMddo 
Por isso, propomos, aqui, com este artigo-roteiro, contribuir para a rediscussão acerca da educação e do ensino remoto, mas, principalmente, chamar a atenção para um aspecto relevante contido nessa polêmica, e muitas vezes negligenciado, quando não silenciado, pelo discurso educacional remoto: a presença/ausência dos corpos, os corpos que se fragilizam e os corpos excluídos pelo ensino remoto. Fazemos isso colocando em análise e em intervenção uma educação remota e o seu plano close-up, que elimina um corpo inteiro, permanentemente em constituição, como enunciador.

No enquadre de uma tela - de computador e/ou celular - a educação vira foco evidenciando um processo de exclusão em massa. Exclusão do corpo, em sua integralidade e possibilidade de composição, do processo educativo de um quantitativo de estudantes e de professores que não possuem acesso ao mundo remoto. Para colocar em análise essa dimensão do close-up esta escrita se compõe de três cenas, a saber: Cena 1: Pandemia e pandemônio: vai passar!(?); Cena 2: Espaços outros e heterotopias: Em uma ofegante epidemia, um pouco de ar para não sufocar; Cena 3/Epílogo: Brechas de uma formação inventiva de professores: A evolução da liberdade. Esta aposta, conceitual e metodológica, das cenas e tomadas, funcionam como propagadores da dimensão crítica e de resistência, possibilidades de afirmar modos autogestionários e inventivos de formar que ligam conhecer e viver à um ethos - uma política - para a produção de vidas livres. Raridades em tempos de educação e controle remotos.

Corta!

\title{
Cena 1: Pandemia e pandemônio: Vai passar!(?)
}

\author{
Num tempo \\ Página infeliz da nossa história \\ Passagem desbotada na memória \\ Das nossas novas gerações \\ Chico Buarque
}

Tomada 1: A tela com os três pares de mãos é minimizada expondo a fotografia de uma escola na tela de fundo. Por trás da tela, referências do lugar de intimidade onde a professora se encontra (cozinha, escritório ou quarto). Ao fundo sons de cachorro latindo, crianças brincando. Som do mouse clicado. Na tela, abre-se um aplicativo. Som de teclado. Inicia-se uma chamada remota. A imagem é de uma professora que, com ar de cansaço, esboça um sorriso. Abaixo, em três quadradinhos menores, a imagem de três alunos. Um deles com a câmera aberta pode ser visto a frente de uma parede branca; os outros dois com a câmera fechada, expõem, um, uma foto recente, e o outro, uma paisagem de praia. A professora dá boas vindas. 
Estamos em casa. Se queríamos um outro mundo... pronto, ei-lo! O desconhecido entrou sem pedir licença. E se tem uma coisa que a pandemia e a necessidade de afastamento social para combatê-la fez foi nos fazer ver e falar sobre nós mesmos, o outro, e o mundo. A pensar o entre. A pensar o tempo e o espaço. A pensar, a educação e a escola em seus velhos e novos contornos. E, quando falamos de pensar, estamos colocando em análise e em intervenção o que temos feito de nós, podendo, com isso, talvez, cartografar (PASSOS; KASTRUP; ESCÓSSIA, 2009) nossos gestos, escolhas, modos de fazer, para poder acompanhar processos e, talvez, inventar modos outros de vida.

Nossas relações passaram a ser remotas. Nossos encontros e conversas, quando possíveis $^{9}$, tomaram uma outra corporeidade. Eliminamos o corpo na sua integralidade e potência enunciativa e passamos a nos ver em close. A distância. Numa presença-ausência que pôs em xeque tanto o sentido de coletivo e das relações, quanto o de intimidade. Assim como nossos rostos, nossas vidas foram postas em telas, em close. A sociedade, as instituições, tudo em close.

Um close acontece quando o foco da câmera está fechado em algo de tal forma que, eliminados outros elementos de composição, passa a tomar uma exclusividade enunciativa. $\mathrm{E}$ não acontece somente com rostos. Outras partes se fosse do corpo, objetos... podem estar em close.

Há os que interpretam o primeiro plano como um objeto parcial, que desmembra um corpo porque existe por aquilo que falta e, por isso, necessita ser reconciliado. Gilles Deleuze e Felix Guattari divergem desta posição. Para eles, o que está em close, em primeiro plano, é um "rosto" e passa a ser uma "máquina abstrata de rostidade"10 (DELEUZE; GATTARI, 1996) tensionando dois eixos: significante e subjetividade.

[...] cada vez que descobrimos em algo esses dois polos - superfície refletora e micromovimentos intensivos - podemos afirmar: esta coisa foi tratada como um rosto, ela foi "encarada", ou melhor, "rostificada", e por sua vez, nos encara. (DELEUZE, 1990, p.115)

Que efeitos de sentido tomam uma educação rostificada, encarada em close? Há possibilidade de uma educação intensiva nesses termos ou ela segue o formato de parcialidade do objeto encarado, necessitando reconciliação com o que falta, ao contrário do que propõem Deleuze e Guattari? E quando a câmera está fechada, ou nas lives, produzindo uma rostidade

\footnotetext{
${ }^{9}$ Uma das maiores reclamações dos professores do ensino fundamental e médio é a impossibilidade de participação dos alunos em aulas virtuais que não se resumem a falta de acesso à internet ou a aparelhos eletrônicos, mas estendem-se a questões emocionais provocadas pelo isolamento, as perdas de parentes e amigos, o desemprego e necessidade da busca de sustento... pelo medo.

${ }^{10}$ Sobre rostidade ver a aula de Bruno Cava: "Deleuze e o cinema (35/40): a imagem rosto" no canal "Horazul", disponível em: https://www.youtube.com/watch?v=180FzWaFY5Q\&t=81s
} 
unilateral, podemos chamar esse processo de educação na perspectiva inventiva? Ou ela se aproximaria mais do bancarismo freiriano ${ }^{11}$ ? Há educação sem encontro? Que possibilidades de encontro existem em uma educação remota?

Essa educação em close, vivenciada nesse momento em que fomos, desde as nossas casas, jogadas no mundo virtual (diferente do que acontece nas redes sociais em que muitas vezes a realidade aparece maquiada), surge com contornos bem definidos, num processo identitário, exposta em suas superfícies refletoras. Produzida por micromovimentos intensivos e expressivos, produtores de condicionamentos, de adaptações que estamos obrigados a encarar, fez com que nossas mazelas sociais e políticas fossem expostas na tela.

Tomada 2: A única câmera de aluno aberta, se fecha. E a professora fica ali. Imagem solitária. Em seu rosto, em cada friso do tempo, em cada poro ampliado, a superexposição de si, as marcas das incertezas que o momento impõe, a opressão de ter que se submeter ao desconhecido e performar, sem que tivesse qualquer preparo ou opção. E os alunos - os três que conseguiram conexão para estarem na aula - com suas não-imagens, permanecem ali, mudos. Uma criança chama: mãe! A professora pede licença, fecha seu microfone e câmera. A tela inteira, estática, emudece. O aplicativo é minimizado e reaparece a escola como fundo de tela.

Para nós professoras, agora, é a escola que toma a cena. A escola que deixamos na sextafeira, 13 de março de 2020, e que precisamos transportar para o quadrado de uma tela. Ela cabe ali? Aos poucos, vamos entendendo que aquela escola não existe mais. Não naquele formato que conhecemos. E o que faremos, então?

Nos atiraram em um lugar outro, desconhecido de uns, pouco explorado por muitos. Um espaçotempo $^{12}$ que desafia as lógicas pelas quais fomos forjadas. Não sabemos o que fazer. E agora, expostas em close, nossos rostos se tornam zonas intensivas que, eliminada a possibilidade enunciativa dos nossos corpos, tomam uma outra dimensão de linguagem. Fomos enquadradas numa caixinha de julgamentos e cobranças por produtividade. Mas produzir o quê?

Passamos então a problematizar como nunca antes o que consideramos como educação. E pensá-la em outro formato é antes de tudo pensá-la. E pensar a nós, professoras, como produtoras de uma educação outra possível.

Fui convidada a dar uma formação para professoras alfabetizadoras da SME-RJ com o tema: leitura e análise linguística. Texto em power point... 357 pessoas "presentes" no encontro... e, da solidão do meu quarto, eu só via o meu texto e a mim. Falei por

\footnotetext{
${ }^{11}$ Sobre bancarismo em Paulo Freire ver "Walter Kohan - Por que ler Paulo Freire em tempos de pandemia?" do canal “Agenciamentos contemporâneos", disponível em: https://www.youtube.com/watch?v=807HR7XfqTc\&t=4489s

${ }^{12}$ A escolha da grafia visa expressar a integração dos conceitos.
} 
40 minutos numa compulsão esquizofrênica, sem nenhum retorno, sem nenhuma troca. Saí dali com uma sensação de vazio absurda. Profa Liliana Secron ${ }^{13}$

Talvez este relato não tenha a pretensão de responder as perguntas, mas, diferentemente disso, de forçar o pensamento a pensar no que temos experienciado e no que estamos nos tornando sob os efeitos dos encontros virtuais/remotos ${ }^{14}$.

A experiência de um encontro presencial é vivida numa composição de olhares, de sons, de gestos, de corpos que faz do encontro-aula, como propõe Deleuze (1997), uma experiência que pode ser comparada à composição de uma orquestra. Compor essa música-aula, na presença, nos permite improvisos, ajustes de volume, de tonalidades, que só se produzem porque existe um coletivo que interage em suas corporeidades.

Estar diante de uma tela, nessa composição apresentada no relato e tantas vezes repetida no ensino remoto, será, no máximo, uma experiência de música solo, geradora de um constrangimento narcísico causado pela visão única de nós mesmas na tela. Somos vistas sem ver, ou vendo pequena parte dos interlocutores por quadrados minúsculos em que mal podemos ver seus olhos.

Essas experiências nos provocaram pensar: que movimentos intensivos nos permitem/exigem uma educação em close? Como podemos fazer da educação remota um espaço de menos produtividade e mais daquilo que alarga o pensamento e produz um espaço de aprendizagem e de fricção consigo mesmo? Como construir remotamente uma educação capaz de promover desejo, afeto, movimento, deslocamentos nesse cenário de perdas de vidas e desequilíbrio emocional, social e econômico? O que vemos quando nos olhamos, rosto a rosto, nas telas? E quando só vemos, durante uma aula, apenas uma tela, sem rostos? Qual a dimensão ética e política do uso de nossos rostos em close nas atividades remotas? Uma live é uma aula? Um conjunto de closes formam um coletivo ${ }^{15}$ ?

Uma ação remota, nesse formato educativo em que fomos bruscamente inseridas, parte da solidão de nossas casas, do nosso lugar de intimidade. Uma solidão que já vinha sendo, a cada dia, capturada pelas lógicas neoliberais através de suas políticas comportamentais, desenvolvimentistas, socio-históricas e humanistas e suas concepções de identidade,

\footnotetext{
${ }^{13}$ Relato realizado durante encontro remoto de grupo de pesquisa Oficina de formação inventiva de professores - OFIP que existe desde 2010, vinculado ao Programa de Pós-Graduação em Educação Processos Formativos e Desigualdades Sociais da Universidade do Estado do Rio de Janeiro. Detalhes em: https://www.facebook.com/Ofip.formacaoinventiva/, https://www.instagram.com/ofip.uerj/, www.ofip.org ${ }^{14}$ Sobre real e virtual ver: Pierre Levy no canal "Fronteiras do Pensamento", disponível em: https://www.youtube.com/watch?v=sMyok16YJ5U e Luiz Fuganti disponível em: https://www.youtube.com/watch?v=OARZYgdxK_s

${ }^{15}$ Sobre o conceito de coletivo ver Liliana Escóssia e Virgínia Kastrup na revista "Psicologia em estudo", disponível em: https://www.scielo.br/j/pe/a/q5rCtwtDCZgpC84gJTcKY8v/?lang=pt
} 
personalidade, consciência, adaptabilidade; e ampliadas pelas experiências tecnológicas globalizantes.

Quando estamos imersos em redes sociais, apesar dela ser considerada para muitos uma forma de estar em companhia, na grande maioria das vezes, há uma solidão que em nós é acessada. Uma solidão do esvaziamento da mente, da imobilização do corpo. Ficamos ali, inertes, esperando o comando, disciplinados, silenciados, voluntariamente. Rolamos o dedo na tela, clicamos, clicamos, recortamos e colamos sem reflexão, sem questionamento. Fomos convencidos de que temos ali o comando, mas só repetimos o que nos é imposto. Ela é, sim, uma solidão do esvaziamento, da exclusão do pensamento, da repetição do mesmo, da dispersão. Um exercício do que chamamos aqui de uma ação-não-ação. É o avesso da criação.

Esta é uma solidão que está longe de ser uma "solidão povoada" a que se referiu Deleuze (1998) registrada no livro "Diálogos", em companhia de Claire Parnet e presente também no Abecedário de Deleuze (1997), entrevista concedida entre 1988-1989, disponível em plataformas do Youtube ${ }^{16}$, que trata de uma experiência muito distinta tanto da experiência vivida nas redes sociais, quanto na proporcionada pelo isolamento social nesse presente pandêmico:

\begin{abstract}
Para mim, duas coisas são importantes: a relação que podemos ter com os estudantes é ensinar que eles fiquem felizes com sua solidão. Eles vivem dizendo: "Um pouco de comunicação. Nós nos sentimos sós, somos todos solitários". Por isso eles querem escolas. Eles não poderão fazer nada em relação à solidão. Temos de ensinar-lhes os benefícios da sua solidão, reconciliá-los com sua solidão. Esse era o meu papel de professor. O segundo aspecto é um pouco a mesma coisa. Não quero lançar noções que façam escola. Quero lançar noções e conceitos que se tornem correntes, que se tornem não exatamente ordinárias, mas que se tornem ideias correntes, que possam ser manejadas de vários modos. Isso só é possível se eu me dirigir a solitários que vão transformar as noções ao seu modo, usá-las de acordo com suas necessidades. Tudo isso são noções de movimento, não de $\operatorname{escola}^{17}$ (DELEUZE, s/p)
\end{abstract}

Pensar a educação como movimento é pensá-la como propulsora do avesso de uma solidão esvaziada e imobilizadora. Ao contrário do que acontece no uso de redes sociais em sua ação-não-ação produtora de um movimento que, contraditoriamente, nos mantém estáticos, a educação que desejamos produzir é desencadeadora de deslocamentos, no sentido foucaultiano ${ }^{18}$ (DIAS; RODRIGUES, 2020), provocados por um exercício de si sobre si mesmo (FOUCAULT, 1994) e que estimula em nossos alunos e em nós a experiência de gostar de estar

\footnotetext{
${ }^{16}$ Vídeo da entrevista de Gilles Deleuze por Clair Parnet disponível em Abecedário de Gilles Deleuze (Transcrição + Vídeo Completo) (clinicand.com)

17 Transcrição no site "Biblioteca Nômade, disponível em: http://www.bibliotecanomade.com/2008/03/arquivopara-download-o-abecedrio-de.html

18 “Meu problema ou a única possibilidade de trabalho teórico que me anima seria deixar [...] o vestígio dos movimentos devido aos quais não estou mais no lugar em que estava há pouco. [...] Trata-se [...] de um traçado de deslocamento, isto é, não de um traçado de edifício teórico, mas do deslocamento pelo qual minhas posições teóricas não param de mudar." (FOUCAULT, 2014, p. 70-71).
} 
com a solidão e povoá-la, de forçar o pensamento a pensar, de aprender a lidar com ela, problematizar com ela, produzir subjetividades ${ }^{19}$, vivê-la intensivamente como experiência e (re)inventá-la. Mas como liberar o pensamento daquilo que nos aprisiona e imobiliza? Como fazer da solidão uma prática de resistência e de liberdade?

Pensar na perspectiva de resistirmos e sermos livres é um movimento que se faz necessário no contexto brasileiro atual. Um momento de tentativa de cerceamento da liberdade de pensamento e de manifestação, e de controle, inclusive, das práticas educativas, numa versão atualizada da ditadura brasileira da década de 1960, "página infeliz da nossa história" e que a educação precisa também problematizar para que não haja reedição.

Tomada 3: Câmera em close no rosto da professora. Ela olha ainda por alguns segundos para a tela, olha em sua volta, levanta e sai. Close na tela.

Corta!!!

\title{
Cena 2: Espaços outros e heterotopias: Em uma ofegante epidemia, um pouco de ar para não sufocar
}

\author{
E um dia, afinal \\ Tinham direito a uma alegria fugaz \\ Uma ofegante epidemia \\ Que se chamava carnaval \\ O carnaval, o carnaval \\ (Vai passar) \\ Chico Buarque
}

Se hoje existem muitos territórios que nos escravizam, existem outros tantos capazes de nos libertar! Todo mapeamento terá brechas! Sempre haverá um espaço onde o olhar não chega, onde o poder não vê. Acreditem, sempre haverá! Pode ser uma festa, uma rede de distribuição de alimentos, as ideias na cabeça de alguém, a internet, um grupo de estudos, um sussurro, um site de filosofia.

Rafael Trindade ${ }^{20}$

Tomada 1: A cena dos rostos em close se repete, como uma caixa de ressonância. Em tela, dessa vez, o encontro de um coletivo de pesquisa ${ }^{21}$. Câmeras e microfones abertos. A expressão é de cansaço e uma certa tensão pela sensação de não dar conta da escola, do ensino e da própria vida.

\footnotetext{
${ }^{19}$ Sobre a descolonização das subjetividades ver Suely Rolnik no canal “AJD - Associação Juizes para Democracia, disponível em: https://www.youtube.com/watch?v=-CwE9x0gn0s

${ }^{20}$ Passagem de texto lido e comentado no podcast "Imposturas filosóficas": https://razaoinadequada.com/portfolio/79-zona-autonoma-temporaria/ publicado em: 18/06/2020.

${ }^{21}$ Referência à Oficina de Formação Inventiva de Professores: www.ofip.org , https://www.instagram.com/ofip.uerj/, https://www.facebook.com/Ofip.formacaoinventiva/
} 
Os quadrados que compõem a cena, dessa vez, no entanto, expressam a possibilidade de produção de presença e de coletivo em um plano de somimagemafeto $^{22}$, uma composição de corporeidades, linguagens e afecções que produzem, no entre, um modo outro de existência. Discussão iniciada.

Rostos em fricção, problematizando o close, compartilham o desejo de forçar a pensar o que pode tensionar a dimensão remota da educação. Uma educação sem lugar-escola, sem deslocamento dos corpos, sem trajeto, sem materialidade do caminho que nos leva até ela, sem rua, mas com uma solidão povoada, produzindo aproximações e deslocamentos.

A rua e a escola como territórios, são espaços pelos quais e com os quais aprendemos a nos deslocar, nos movimentar, a circular com nossos corpos físicos, reais, palpáveis, abraçáveis. Lugares singulares de encontro. E o encontro é a dimensão do que nos move e nos singulariza.

As possibilidades corpóreas de mobilidade ou não-mobilidade pautam a nossa relação com esses territórios, com seus habitantes e conosco. Mesmo quando se está privado de liberdade é a partir das possibilidades movimento/não-movimento que essas relações se estabelecem. Só que agora, não é mais uma questão de mover-se ou não se mover. O que nos foi retirado foram os próprios territórios. Não há rua, nem escola.

Fomos imersos, de dentro de nossas casas, em um lugar sem lugar. Heterotópico ${ }^{23}$ ? Lugar de corpo sem corpo, impalpável. E percebemos que, mesmo já vindo circulando também por ele há tempos, não sabemos viver nele. Ele não é da nossa natureza. A dimensão remota não consegue compor e expressar o que é do corpo. E a educação? E a escola nesse novo contexto? Conseguem?

A heterotopia de Foucault (2013) é um espaço outro que, ao contrário das utopias, não possuem lugar no real, é real e se manifesta na relação sujeitoespaçotempo por entre os corpos, a linguagem e os discursos (SECRON, 2020). Pensar o mundo virtual como heterotópico, portanto, é pensá-lo em sua materialidade e produzir com ele corporeidades e circulações outras, possibilidades outras de existência.

A escola sempre foi, e é até hoje, uma instituição projetada para manter o mundo que se tem promovendo a adaptação das existências e a docilidade. O lugar da ordem, da disciplina, da obediência, do silêncio imposto, da lógica das filas e da divisão asséptica de meninas e meninos. Mas também é o lugar de produzir linhas de fuga, que tensionam esse lugar de

\footnotetext{
22 A grafia expressa a integração entre os conceitos som, imagem e afeto.

${ }^{23}$ Sobre heterotopias, ver Michel Foucault em "Michel Foucault: Las Heterotopías “ no canal "Espacio e sociedade" disponível em: https://www.youtube.com/watch?v=4O-z_O0m24Y e/ou a participação de Margareth Rago no X Seminário internacional: tempo livre na cidade, no canal "Escola da cidade", disponível em: https://www.archdaily.com.br/br/802806/margareth-rago-inventar-outros-espacos
} 
controle. O lugar do toque, do despertar de desejos, da hora do recreio, do cafezinho do intervalo, onde se faz roda e se mistura todo mundo. O lugar das resistências... das insurgências.

O mesmo lugar onde se encontram os conteúdos programáticos divididos por disciplinas, as habilidades e competências, a preparação para o mercado de trabalho é também o lugar da ciência e das artes. A escola é um lugar de pensamento.

Um lugar de disputas diárias por sentidos, onde temos como aliados as subjetividades dos nossos corpos, a sedução dos olhares, dos gestos, a possibilidade do toque, da negociação, da discussão. O lugar onde os corpos são conformados, controlados, enformados, também é o lugar de onde podemos derivar do que somos. É o lugar de produção de subjetividades, de promoção de diferenças. O lugar de experienciação do convívio com o diverso, com o diferente de mim, do ser coletivo. E o sentido de coletivo ali é corpóreo, visível, palpável. A escola é o lugar do encontro.

Essa escola, da forma que a concebemos, por entre as brechas que produzimos, tem como matéria prima o encontro e o que emerge da fricção que o encontro produz. Encontrar e conversar é um desafio necessário numa sociedade que cada vez mais se individualiza, se identidariza.

E agora? Não há mais escola. Não acessamos mais o lugar-escola da forma com que o concebemos. Vivemos um distanciamento dos corpos que nos coloca em close, frente à tela, sem corpos para resistir. E se não há corpo como produzir presença? Ou seria a presença por vias de uma corporeidade outra que, tensionada, disputa novos sentidos?

Como nos posicionar, professoralmente em território virtual? Quais aprendizagens e desaprendizagens são necessárias para circularmos e produzirmos saberes numa educação remota? No presente pandêmico, seguimos afirmando que o processo de formação é produção de subjetividade? Como produzir remotamente possibilidades de experiências de pensamento e problematização? Como evitar o paradoxo da formulação "seja inventivo" simplificador da transposição de uma educação presencial para uma educação remota? Como mantermo-nos no campo da racionalidade sensível, fugindo do lamento, nesse momento de tantos desafios e dores? Como podemos acionar saberes remotamente em uma educação em que o que circula predominantemente é a informação?

Mesmo com a tentativa de nos adaptar e compreender o que passamos no presente, tanto no que se refere a uma vida em distanciamento social, quanto pelas de experiências remotas, fomos forjados na corporeidade do mundo que produz o coletivo no encontro dos corpos. Sendo assim, por mais que, de alguma forma, já estivéssemos interagindo com o mundo virtual, nesse momento, o impedimento de circulação e ocupação de espaços, nos desestabiliza e tensiona. 
Conversando com Deleuze e Guattari (2004) atentamos para o fato de que o que move o pensamento são os efeitos do mundo em nós, que eles chamam de afecções - estados no nosso corpo que ainda não tem a ver com a ação, mas que guardam em si a ideia de movimento. Sendo assim, será que não é justamente essa desestabilização e tensão vividas no presente que nos mantém vivos num contexto de tantas perdas?

Suely Rolnik ${ }^{24}$, conversando com Deleuze e Guattari, nos dá algumas pistas para pensar sobre o tema quando diz ser a existência, um encontro entre as experiências pessoal e extrapessoal. Em que a experiência pessoal tem relação com o script do nosso modo de existência, suas respectivas funções e as dinâmicas das relações entre eles, seus universos de referência e seus códigos, suas representações, seus sentidos, que o situa na cartografia sociocultural na qual ele está inserido; já a experiência extrapessoal é a que se compõe de um ecossistema do qual ela é um elemento responsável pelo seu equilíbrio vital juntamente com os outros seres que o compõem. Sobre essa última Suely diz

\begin{abstract}
Elas atingem nosso corpo produzindo nesse corpo um estado de intensidades que é específico, que tem qualidades específicas, mas enquanto intensidade, enquanto frequência de vibração porque não tem palavra, não tem imagem, não tem linguagem, não tem gesto, não tem nada. E, no entanto, não é um nada, não é um vazio. É um cheio. É um cheio de um estado que é real e alias eu diria que a dimensão do real é exatamente essa. O real do corpo. Dos efeitos do mundo no nosso corpo naquele momento. E esse estado, ele fricciona nossa experiência enquanto sujeito pessoal porque ele fricciona a cartografia na qual eu me encontro estruturada e na qual eu me oriento e me situo. Porque aquilo que está ali em germe, no meu corpo, não encontra possibilidade de lugar nessa cartografia. Então tensiona, fricciona essa cartografia. Esse estado produz no sujeito um estado de estranhamento e a fricção entre esse estado e o sujeito pessoal produz uma experiência de desestabilização. Porque nosso repertório fica desestabilizado, nossa autoimagem, a imagem do mundo, tudo se desestabiliza. A linguagem que a gente dispõe não dá conta disso. Linguagem no sentido amplo e não só verbal. Essa fricção, essa desestabilização, nos coloca num estado de fragilidade e funciona como uma espécie de alarme vital em que a vida diz que ela está sufocada naquela forma em que ela se encontra atualizada porque tem algo já em outro lugar e aquilo passa a ser sufocante. (ROLNIK, s/p) ${ }^{25}$
\end{abstract}

Ao sermos jogados no mundo virtual, percebemo-nos em estado de desequilíbrio. Um desequilíbrio manifesto de forma extrapessoal, que não possui materialidade, e nos afeta, e nos sufoca, e nos coloca em risco tanto quanto o vírus que nos acomete nesta pandemia.

Este lugar de desequilíbrio que nos coloca em estado de fragilidade, por sua vez também é de onde operamos o nosso corpo vibrátil que aumenta o nosso grau de suportabilidade para viver o presente (ROLNIK, 2007), nos põe em movimento, e tensiona nossa capacidade inventiva.

\footnotetext{
${ }^{24}$ Fala de Suely Rolnik no podcast “\#81 Desejo, pensamento e ação (com Suely Rolnik)" no Spotfy Imposturas Filosóficas, 3 jul 2020 em que Rafael Lauro e Rafael Trindade entrevistam a pesquisadora. Disponível em: https://razaoinadequada.com/portfolio/81-desejo-pensamento-e-acao/

${ }^{25}$ Idem
} 
Essa ofegante pandemia nos força a buscar ar para não sufocar. Mas como? Seguimos em busca de ar apostando naquilo que nos força a pensar e abrir a produção de espaços outros.

Nessa tentativa, nos mantemos problematizando: aulas em que o professor fala e os alunos escutam são facilmente transferíveis para uma plataforma online, mas qual é o alcance do que está sendo dito (tanto no sentido de se há alguém que acessa, quanto de que, uma vez acessada, ela afeta quem ouve)? Não estaríamos trocando o "cuspe e giz" dos quadros negros, pelo "cuspe e luz" dos computadores e celulares numa releitura do bancarismo freireano? Estaríamos, com nossas aulas remotas, reforçando as lógicas mercadológicas, não problematizadoras, representacionais e opressoras dos conteúdos escolares, e ignorando o presente com suas complexidades tanto de experiência pandêmica quanto da necropolítica ${ }^{26}$ fomentada pelo atual governo de nosso país?

Gilles Deleuze, em seu Abecedário, nos diz que, uma aula é um espaçotempo muito especial, pelo seu caráter de continuidade, de sequência, e de movimento a que se acrescentam o caráter participativo de todos os sujeitos presentes que a compõem. Para ele aula é ensaio, entusiasmo, emoção, movimento (DELEUZE,1997, s/p).

Podemos dizer, portanto, que Deleuze aposta na relação sujeitoespaçotempo, como na heterotopia foucaultiana, para a produção de uma aula. Um espaço que acolhe a dimensão da invenção de forma ética, estética e política ${ }^{27}$ (DIAS, 2019), e, como colocamos desde o início deste artigo-roteiro, reforça e importância da crítica e da resistência para problematizar a educação remota, mas, antes disso, problematizar o próprio conceito de educação e suas práticas presenciais produzidas até então.

Deleuze ressalta, ainda, o caráter coletivo e inventivo que possui uma aula (e acrescentamos, seja ela presencial ou remota), e o movimento por ela produzido que permite o deslocamento do lugar puramente da informação para que seja possível toma-la como vida e transformação. Poderíamos afirmar, dessa forma, que uma live, como uma conferência, citada por Deleuze, não se aproxima do que seja uma aula. Sendo assim, seria possível realizar uma educação remota que seja um lugar de aprender a viver, um espaço de exercício de experienciar a relação consigo, de se constituir uma política de cognição que liga vida-conhecer-ser, de produzir-se a si singularizando-se?

\footnotetext{
${ }^{26}$ Sobre necropolítica ver conversa com Silvio Gallo com o tema "Bionecropolítica e(m) Foucault” no projeto "Babados na pós" da PPG Educação da FFP UERJ, disponível em: https://www.youtube.com/watch?v=DMkJYz96ADk

${ }^{27}$ Sobre ética, estética e singularidade ver a fala de Félix Guattari disponível em: https://www.youtube.com/watch?v=2CPoRBZ7Uc4
} 
Talvez, seja importante destacar, neste ponto do texto, que, essa tarefa permanente de problematização da educação remota pelos professores torna-se, para nós, a busca de ar para não sufocar, signo de produção da vida no presente pandêmico.

Tomada 3: Fim do encontro. Os rostos já mais tranquilizados, voltam a sorrir. É a "montanha russa" de sentimentos cotidiana expressa no espaço-tempo da tela. O grupo se despede. Fecham-se um a um os closes. As singularizações vibram intensivamente durante a semana e retornam outras no próximo encontro.

Corta!!!

\title{
Cena 3/Epílogo: Brechas de uma formação inventiva de professores: A evolução da liberdade
}

\author{
Meu bem, vem olhar \\ Vem ver de perto uma cidade a cantar \\ A evolução da liberdade \\ Até o dia clarear \\ É o estandarte do sanatório geral! \\ Vai passar! \\ Chico Buarque
}

É preciso ter coragem de viver essa verdade. Viver a verdade exige da gente muitos riscos e o risco é signo da liberdade ${ }^{28}$

Profa. Rosimeri Dias

Tomada 1: Novo encontro. Uma poesia é compartilhada na tela e os rostos em quadriculado reduzidos à lateral direita. Trata-se de um exercício de escrita de si (FOUCAULT, 2002) que passa a ser proposto, desde que deixamos o presencial, a cada início de encontro do grupo ${ }^{29}$. Uma forma de pensamento sobre o presente, de cuidado de si e de produção do coletivo (DIAS; RODRIGUES, 2019). Há uma voz que lê e olhos que reagem ao somimagemafeto da leitura e mudam a paisagem da tela e sua rostidade.

Pedaços de nós ou nossos pedaços?

Uma não hierarquização nos encontros,

A escrita partilhada com o grupo....

O poema em diversas falas, $\mathrm{o}$ texto narrativo em outras.

Vozes que saltaram para fora de uma tela, que este ano, insistiu em nos enquadrar.

Mas nossos corpos, num anti-especismo literário místico inclusivo e artístico, são insurgentes e inventaram uma forma outra de abraçar.

Abraçar com palavras ditas e não ditas, aquilo que emerge e impregna, saltando através da tela, para encontrar o olhar do outro.

\footnotetext{
${ }^{28}$ Retirado do vídeo "Conversas sobre Foucault: Rosimeri Dias fala sobre "Foucault e a formação inventiva de professores", disponível em: https://www.youtube.com/watch?v=JXcPSeBt18k

${ }^{29}$ Trabalho forjado na orientação coletiva da OFIP, foi estrategicamente pensado por meio da liga entre Ailton Krenak (2019) e Michel Foucault (2002). Os inícios das atividades aconteceram com a leitura de pequenos textos, poesias, passagens escritas que pudessem singularizar o presente na atividade de orientação de estudantes de graduação e pós-graduação.
} 
Sigamos, 2021 batendo a porta, novo ciclo na vida, na OFIP.... Nada sabemos do que virá, então...

Naveguemos, surtemos, descansemos, trabalhemos, amemos, porque não sabemos o que nos espera, mas nesse território, poderemos inventar uma maneira outra de partilhar nossos possíveis. (Líbia Busquet)

“Que lindo!": expressão geral do grupo após a leitura da poesia. A paisagem agora mostra os rostos como esfera de produção de subjetividade, de transformação de si, ganhando a rostidade de um vibrátil, intensivo, produtor desse somimagemafeto que vaza as telas dos computadores tocando corpos distantes e expõe as possibilidades de força ativa de um encontro virtual.

As rostidades ali postas, no momento das leituras, vibram no esforço de composição entre a fragilização fronteiriça, o individual e o coletivo dos pontos que tensionam a constituição de uma política cognitiva e de produção de sentidos para o que vimos nos propondo enquanto profissionais da educação.

Pensar o ensino remoto não está descolado de pensar o que vimos fazendo da escola que temos e de buscar análises e intervenções que possibilitem a produção de uma escola outra tanto virtual, quanto a física, no momento em que retornamos.

Durante esse processo, observamos que a dimensão remota da educação coloca em close uma política cognitiva informacional. (DIAS, 2011). Tal política se afirma como um ethos que criva a cognição como um processo de solução de problemas, de representação de mundo, colocando essa política cognitiva, em uma perspectiva que deixa de fora possibilidades de invenção de si e do mundo.

Por isso, apostamos em nossa capacidade de produção de linhas de fuga para por em prática uma política produzida por insurgências e invenção, que tenha a arte e a escrita de si (FOUCAULT, 2002) como elementos promotores de pensar e de fazer educação como movimento, heterotópica, em que o espaço remoto - como espaço outro - aconteça com os princípios de uma formação inventiva de professores (DIAS, 2019). Por sua aposta ética, estética e política. Essa perspectiva problematiza não somente que a escola, a educação, mas também que sociedade estamos produzindo com nossas escolhas e políticas vigentes e produzem efeito nas políticas educacionais.

Vimos sofrendo, nos últimos anos de forma acentuada, a pressão para a privatização do ensino guiada pelos interesses de grandes grupos financeiros; a desvalorização docente tanto no que diz respeito a direitos perdidos, quanto ao questionamento da ética docente, da ciência e da existência da própria escola, inclusive com a tentativa de implementação da "educação domiciliar"; tentativas de fechamento de universidades públicas federais e estaduais por todo 
Brasil $^{30}$, condenação de livros literários, tentativa de alteração dos livros de história principalmente no que diz respeito à exaltação da ditadura e à crença no terraplanismo ${ }^{31}$.

O presente nos convoca a pensar a atuação e a formação de professores e pedagogos, escolas e universidades. Formar professores não pode ser sinônimo de prepará-los para o uso de aplicativos e redes sociais para realizar atividades motivacionais e que desenvolvam habilidades e competências previamente estabelecidas, ou ainda para atuarem em frente às câmeras, como propõem diversas empresas contratadas para realização das formações que vem sendo oferecidas.

Além disso, a sobrecarga de trabalho e pressão por produtividade sem que se consiga atingir os alunos de forma efetiva, em muitos casos, vem desestimulando e adoecendo a classe. Há falas comuns retiradas de reuniões, que temos participado, que expressam essa dimensão de sobretrabalho, tais como: “Já não sei mais o que fazer para chegar aos meus alunos. Os poucos que respondem ao que posto não alcançam o que propus". E, ainda, "tenho que fazer lives com os alunos numa plataforma de conversas...Olho para cada aluno e vejo nos rostos que não entendem o que estamos fazendo ali, na verdade nem eu"; "não julgo os meninos, já não aguento mais tanto trabalho remoto, tantas horas produzindo, sem na verdade compreender o que passamos...Para onde estamos caminhando, é o que me pergunto sempre".

Como, então, atender a essa convocação do presente? Com que tipo de dispositivo? Como praticar uma formação que não nos desse forma, mas nos colocasse em ação, numa perspectiva inventiva?

A função de uma formação inventiva não é dizer aos outros o que eles devem fazer,
ou ainda, transmitir competências e habilidades para ensinar os outros, ou resolver
problemas de maneira nova. Sua função é constituir uma política de cognição
(Kastrup; Tedesco \& Passos, 2008) como uma atitude incorporada por meio das
análises e das intervenções. Uma atenção ao presente vivo da experiência de se formar
e de formar os outros. O intuito é polemizar os postulados, as naturalizações aceitas,
sacudindo as certezas, os modos de fazer e de pensar, retomar as avaliações das regras
e das instituições e, neste contexto, ensaiar. (DIAS, 2015, p.200)

Trata-se de uma proposta de experiência modificadora de si (FOUCAULT, 1994), produzida por micropolíticas ${ }^{32}$ que tensionam a necessidade de reposicionamento no presente

\footnotetext{
${ }^{30}$ Sobre o fechamento da UERJ, matérias disponíveis em: http://asduerj.org/v7/nota-de-repudio-e-de-indignacaoda-associacao-dos-docentes-da-universidade-do-estado-do-rio-de-janeiro-asduerj-referente-as-acoes-criminosasde-parlamentar-bolsonarista/ e http://asduerj.org/v7/nota-de-repudio-e-de-indignacao-da-associacao-dosdocentes-da-universidade-do-estado-do-rio-de-janeiro-asduerj-referente-as-acoes-criminosas-de-parlamentarbolsonarista/

${ }^{31}$ Explicação didática em resposta à disseminação da ideia de terraplanismo dada pelo professor Douglas Gomes, disponível em: https://www.youtube.com/watch?v=O1BbjK-qIG4

${ }^{32}$ Sobre micropolíticas ver Luiz Fuganti no seu canal, disponível em: https://www.youtube.com/watch?v=jvb0n5xqdSs
} 
e acompanhamento de processos, de produção de subjetividade, de transformação de si e do mundo, para se poder, talvez, tecer modos outros de viver.

Como forjar modos outros de viver em um tempo em que os corpos não vistos nas telas de computadores e celulares, mas que ainda estão ali, sentidos, num presente de um mundo que se fez caduco, sem projetar futuro algum, por vias de uma pandemia que nos consome? Talvez neste estudo, possamos pensar os modos de vida atuais dos sujeitos que estão envolvidos com a dita educação remota como quem toma os planos do cinema como dispositivo de invenção de si e do mundo. Cinema, pelos close-ups, tomadas e cenas que nos aproximam, fazendo linhas de fuga na docência, como vetor problematizador da vida que atualmente nos atravessa, como veículo que pode promover um novo modo de pensar (DELEUZE,1990), questionando sobre as imagens do pensamento, possibilitando a produção de sujeitos outros.

Talvez seja possível dizer que, diante das urgências de uma educação remota, ainda assim, a não submissão às totalizações pode apontar um caminho para geração de vida mais potente. Encarando deste modo, apostamos na utilização dos modos de produção contemporâneos como um caminho. Afirmamos o pensamento como pulsão, invenção como potência, numa perspectiva de ação pedagógica que impulsione uma aprendizagem inventiva ${ }^{33}$ e ações de modos outros.

Reforçamos, no entanto, que uma educação remota não substitui, de forma alguma, a potência dos encontros presenciais. Em primeiro lugar pela exclusão que ela promove por não ser uma educação acessível para todos. E não falamos aqui de acesso a aparelhos eletrônicos ou a internet, mas de uma estrutura social que permita desde um ambiente adequado de estudo até a capacidade de relação autônoma com sua solidão permitindo que ela seja "extremamente povoada" como propõe Deleuze (1997). Em segundo lugar porque acreditamos que uma educação se faz de encontros e conversas, de contato, de toque, de corpos inteiros se afetando de forma integral, de experiências coletivas que não ocorrem em close-up.

Propomos, assim, pensar como essa outra forma de encontro, de educação, com toda sua materialidade e potência, pode extrapolar os modos representacionais e reprodutivistas que nos enformam, controlam e limitam ${ }^{34}$.

\footnotetext{
${ }^{33}$ Sobre aprendizagem inventiva, Virginia Kastrup fala no canal "FMPuper" disponível em: https://www.youtube.com/watch?v=Sz7-cLdgsVk

${ }^{34}$ Sobre "A produção da vida nos territórios escolares: entre universidade e escola básica" ver Rosimeri de Oliveira Dias, no canal "Infância e juventude" disponível em: https://www.youtube.com/watch?v=aQpbAFof$\underline{8 \mathrm{~A} \& \mathrm{t}=106 \mathrm{~s}}$
} 
Talvez a invenção seja ponto chave da nossa realidade atual, ante uma educação remota, pois o pensamento não é inerte, oferecendo movimento, que nos retira da imobilidade e de sua suposta naturalização. Então, aprender inventivamente, ainda que no modo remoto, pode abrir caminhos para exercitarmos uma aprendizagem efetiva, artística, possibilitando vislumbrar um novo mundo nessa aprendizagem que, mesmo sem sala de aula, fora dela, carrega sujeitos de um cenário pandêmico contemporâneo. Pensando deste modo,

\section{O ponto de vista da arte revela-se como uma forma superior de problematização, ou, em outras palavras, significa colocar-se frente ao processo de aprender do ponto de vista da problematização, que define, então, uma forma de relação com os objetos, com os modos de ação e consigo mesmo (KASTRUP, 2001, p. 26).}

Percebemos como crucial que práticas pedagógicas não sejam entorpecedoras, reprodutoras, mas que trabalhem a serviço de um horizonte possível, que promovam e provoquem junto aos estudantes, mesmo que remotamente, produções com o auxílio de elementos de arte com suas várias linguagens, que se façam como força inventiva de possibilidades outras. Somos lembrados que, se não for montada uma máquina revolucionária capaz de carregar o desejo e os fenômenos de desejo, este continuará sendo manipulado por forças de opressão e repressão, promovendo ameaças, por dentro, as máquinas revolucionárias (DELEUZE, 1992).

Importa que nos desloquemos dos clichês do mundo moderno remoto, para que possamos repensar um ethos no contemporâneo. Então, a arte, o teatro, o cinema, as poesias, talvez, promovam uma abertura para auxiliar nisso. Como saída coletiva, que liga crítica e resistências, a arte cria e recria a vida, o mundo.

Aqui, é bom relembrar que o "Vai passar", como dito desde o início, é expressão do desejo de resistir. Questão importante que atravessa o artigo para pensar de forma a nos reinventar, mesmo neste momento em que somos rostos enquadrados em telas, pode se tornar uma diretriz das nossas práticas pedagógicas.

Meu bem, vem olhar
Vem ver de perto uma
Cidade a cantar
A evolução da liberdade
Até o dia clarear
Chico Buarque

Para ver de perto, nas práticas que nos ligam - as três professoras - a uma formação inventiva de professores, operamos por um virtual que comporta gestos de encontros e conversas - que aproximam conhecer, fazer e ser - para atualizar permanentemente o que comparece de problematização, de desnaturalização e de coemergência entre políticas de cognição autogestadas em cada dia e se aproxima de uma obra experiencial de feitura de si e de mundos, sendo a arte uma parceira permanente. Em tais práticas e exercícios de uma formação inventiva de professores, desaparecem os lamentos, pois há sempre algo a fazer: algo facultativo, não obrigatório, porém inevitavelmente voltado a engendrar um cotidiano libertário. E o que seria esse cotidiano em tempos de educação remota? 
Ousamos afirmar que seria aquele que faculta, na arte de constituir, hoje, uma ética de si. Tarefa urgente, já enunciada por Foucault (2004), Dias e Rodrigues (2020), politicamente fundamental de resistência ao poder político, que é a relação de si para consigo, uma prática de produção de si, uma política do eu.

O exercício de uma formação inventiva de professores é o de criação de equipagens para enfrentar e ampliar o grau de suportabilidade para viver o presente e inventar a si e o mundo. $\mathrm{O}$ que temos hoje, nas micro relações em close que nos conectam e criam outros encontros e conversas para escapar do lamento e nos fortalecer.

Formar, neste sentido, como um cuidado de $\mathrm{si}^{35}$, como um processo de produção de subjetividade, como uma dimensão ascética, é o que permite ao sujeito adquirir e dizer o discurso verdadeiro. A verdade, escutada e recolhida, como se deve, entranha-se no sujeito, tornando-se regra de conduta. Assim como é necessária uma arte para ampliar a vida, para falarler-escrever-pensar-estudar, é necessário uma experiência e uma habilidade para acolher uma escuta para si e para outros, para escutar o que amplia o nosso grau de potência para a invenção é fundamental uma economia dos gestos e das palavras, um silêncio ativo e um certo recolhimento que se opõem a lógicas aceleradas e distantes como as que existem hoje em função da necessidade de nos mantermos vivos. Se o distanciamento físico protege a vida, ao mesmo tempo, dificulta, sem impossibilitar, uma educação que se propõe a se constituir como uma equipagem para práticas mais libertárias.

Saímos de nossas escolas no dia 13 de março de 2020 e já não somos as mesmas. Com nossos corpos inteiros, fomos aprendendo, fora da escola, sobre nossa relação com ela, com o mundo e conosco. Uma relação com a verdade que nos provoca o pensamento para construir uma arte de viver, não consensual, bela e livre ${ }^{36}$.

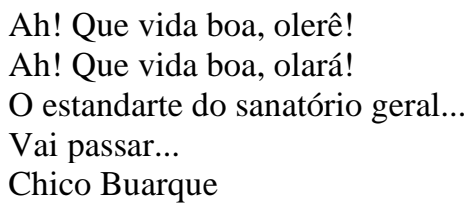

Sobem os créditos ao som do refrão de "Vai passar"...

Corta!

\section{Referências}

DELEUZE, G. A imagem-movimento. São Paulo: Brasiliense, 1990.

\footnotetext{
${ }^{35}$ Sobre cuidado de si ver a aula de Roberto Machado no canal "PPGH - UFG" Disponível em> https://www.youtube.com/watch?v=5CvDaT4FPo0\&list=PLo7cTHyeJ4-vd67ylvWReqTiXfPesQwLP

${ }^{36}$ Sobre viver uma vida livre ver Claudio Upiano no canal "cclulp2008" disponível em: https://www.youtube.com/watch?v=5AcXIOUbsd8
} 
DELEUZE, Gilles. L'abécédaire Gilles Deleuze. Paris: Éditions Montparnasse, 1997.

Videocassete. Legendado em português pelo MEC, TV Escola.

DELEUZE, Gilles. Conversações. Trad. Peter Pál Pelbart. Ed. 34: Rio de Janeiro. 1992.

DELEUZE, G; GUATTARI, F. Ano zero-rostidade. Mil platôs Capitalismo e

Esquizofrenia, v. 3. Rio de Janeiro: editora 34, 1996.

DELEUZE, Gilles; GUATTARI, Felix. O que é a filosofia? São Paulo: Editora 34, 2004.

DELEUZE, Gilles; PARNET, Claire. Diálogos. São Paulo: Ed. Escuta, 1998.

DIAS, Rosimeri de Oliveira. Deslocamentos na formação de professores: aprendizagem de adultos, experiência e políticas cognitivas. Rio de Janeiro: Lamparina, 2011.

DIAS, Rosimeri de Oliveira. Formação inventiva de professores. Rio de Janeiro:

Lamparina, 2012.

DIAS, Rosimeri de Oliveira. Pesquisa-Intervenção e formação inventiva de professores.

Revista Polis e Psique. Vol 5, págs (193-209), 2015. Disponível em: file://C:/Users/1secr/Downloads/53949-238491-1-PB\%20(1).pdf Acesso em: 6/7/2021.

DIAS, Rosimeri de Oliveira. formação inventiva de professores por entre tessituras ética, estética e política de escritas acadêmicas. In: Revista Childhood\&Philosophy. Rio de Janeiro: UERJ, 2019. Disponível em: https://www.epublicacoes.uerj.br/index.php/childhood/article/view/44236/31759

DIAS, Rosimeri de Oliveira; RODRIGUES, Heliana de Barros Conde. Escritas de si: escutas, cartas e formação inventiva de professores entre universidade e escola básica. Rio de Janeiro: Lamparina/FAPERJ, 2019.

DIAS, Rosimeri de Oliveira; RODRIGUES, Heliana de Barros Conde. Deslocamentos, invenção e formação outra - em companhia de Foucault. In: Revista Reflexão e Ação. Santa Cruz do Sul: UNISC, v. 28, número 3, 2020, p. 166-180. Disponível em file:///C:/Users/rosim/Downloads/14278-66032-3-PB.pdf Acesso em: 23 jun 2021. Acesso em: 01 jul 2021.

FOUCAULT, Michel. História da sexualidade 2: o uso dos prazeres. $7^{\mathrm{a}}$ ed. Rio de Janeiro: Edições Graal, 1994.

FOUCAULT, Michel. A escrita de si. In: FOUCAULT, Michel. O que é um autor? Lisboa: Veja, 2002, p. 129-160.

FOUCAULT, Michel. A hermenêutica do sujeito. São Paulo: Martins Fontes, 2004.

FOUCAULT, Michel. O corpo utópico, as heterotopias. São Paulo: n-1 Edições, 2013.

FOUCAULT, Michel. Do governo dos vivos. São Paulo: Martins Fontes, 2014

KASTRUP, Virgínia. Aprendizagem, arte e invenção. Psicologia em Estudo, Maringá, v.6, n. 1, p. 17-27, jan./jun, 2001. Disponível em:

https://www.scielo.br/j/pe/a/NTNFsBzXts5GHp4Zk8sBbyF/?lang=pt Acesso 01 jul 2021.

KRENAK, Ailton. Ideias para adiar o fim do mundo. São Paulo: Companhia das Letras, 2019.

ROLNIK, Suely. Cartografia Sentimental: transformações contemporâneas do desejo.

PortoAlegre: Sulina, 2007.

SECRON, Liliana. Salas de leitura e suas heterotopias como dispositivo para uma formação inventiva de professores. 2020. Dissertação (Mestrado em Educação). Rio de Janeiro: Faculdade de Formação de Professores da Universidade do Estado do Rio de Janeiro FFP-UERJ, Programa de Pós-graduação em Educação - Processos Formativos e Desigualdades Sociais. Disponível em: https://drive.google.com/file/d/1aVw5pr6cehjYlskyXhb9lUELhZpiPZJ/view Acesso em: 1/5/2021.

PASSOS, Eduardo; KASTRUP, Virgínia; ESCOSSIA, Liliana. Pistas do método da cartografia: pesquisa-intervenção e produção de subjetividade. Porto Alegre: Sulina, 2009. TRINDADE, Rafael. Taz - por que zona?. jun 2020. Disponível em: https://razaoinadequada.com/2018/06/20/taz-por-que-zona/ 


\section{SOBRE AS AUTORAS}

Rosimeri de Oliveira Dias. Doutorado em Psicologia, UFRJ; Professora Associada do Departamento de Educação e do Programa de Pós-Graduação em Educação Processos Formativos e Desigualdades Sociais (UERJ) - Brasil; Grupo de pesquisa Oficina de Formação Inventiva de Professores (OFIP/CNPq); Procientista UERJ; Editora da Revista Interinstitucional Artes de Educar (RIAE/UERJ); Vice Coordenadora do FEPAE/Nacional/ANPED. Contribuição de autoria, escrita, obtenção de financiamento FAPERJ, supervisão, revisão e edição. Lattes: http://lattes.cnpq.br/4701136188544538

Liliana Secron. Doutoranda em Educação no Programa de Pós-Graduação Processos Formativos e Desigualdades Sociais, UERJ; Professora da Secretaria de Estado de Educação (SEEDUC-RJ) e da Secretaria Municipal de Educação (SME-RJ) - Brasil; Grupo de pesquisa Oficina de Formação Inventiva de Professores (OFIP/CNPq); Contribuição de autoria: Escrita - Primeira Redação, Escrita - Revisão e Edição, Investigação, Metodologia. Lattes: http://lattes.cnpq.br/9656039686462211

Líbia Busquet. Doutoranda em Educação no Programa de Pós-Graduação Processos formativos e desigualdades sociais, UERJ; Professora da Fundação Municipal de Educação de Niterói/RJ - Brasil. Grupo de Pesquisa Oficina de Formação Inventiva de Professores (OFIP/CNPq). Atriz e cantora. Contribuição de autoria: Escrita - Revisão e Edição, Investigação. Lattes: http://lattes.cnpq.br/8885480289835743

\section{Como citar este artigo (ABNT):}

DIAS, Rosimeri de Oliveira; SECRON, Liliana; BUSQUET, Líbia. Educação remota e pandemia em close-up. Revista Práxis Educacional, Vitória da Conquista, v. 18, n. 49, 2022. https://doi.org/10.22481/praxisedu.v18i49.9121 